\title{
Vertebrectomia total e estabilização com pinos e polimetilmetacrilato como tratamento para luxação entre vértebras torácicas em cão - relato de caso*
}

\section{Total vertebrectomy and stabilization with pins and polymethylmethacrylate as treatment for thoracic vertebral luxation in a dog - case report}

\author{
Alefe Luiz Caliani Carrera, ${ }^{* *}$ Isabela Ferraro Moreno, ${ }^{* * *}$ Ricardo Requena, ${ }^{* * * *}$ \\ Gislaine Aparecida Garcia Refundini, ${ }^{* * * *}$ Aricia Gomes Sprada******
}

Resumo

As lesões decorrentes de atropelamento são as principais causas de fraturas e luxações vertebrais, ocasionando graus variáveis de injúrias vertebrais e medulares. O presente trabalho tem como objetivo relatar a ocorrência de lesão traumática em coluna vertebral de cão sem raça definida, com quatro anos de idade, resultando em luxação T11-12, com exposição de T11 e secção medular, estando o paciente paraplégico, com sinais de lesão em neurônio motor superior e ausência de nocicepção profunda em membros pélvicos. O tratamento de escolha foi a vertebrectomia de T11, associada ao alinhamento de T10-12 com introdução de pinos e fixação com polimetilmetacrilato (PMMA) associado à ceftriaxona. Em decorrência de lesão na pleura parietal no trans-cirúrgico, optou-se pela toracostomia para introdução de tubo torácico, o qual permaneceu no paciente por quatro dias. No pós-operatório, o paciente apresentou recuperação satisfatória, sendo recomendado aos tutores a confecção de cadeira de rodas a fim de facilitar sua locomoção. A técnica mostrou-se satisfatória para minimizar as infecções passíveis de ocorrência em fraturas expostas, bem como melhorar a qualidade de vida do paciente, evitando-se dores crônicas.

Palavras-chave: cirurgia veterinária, coluna vertebral, neurologia, toracostomia, traumatismo da medula espinhal.

\begin{abstract}
Injuries resulting from being run over are the leading causes of vertebral fractures and dislocations, causing varying vertebral and spinal injuries. The present study aims to report the occurrence of traumatic injury to the spine of a mixed breed dog, aged four years, resulting in a T11-12 dislocation, with T11 exposure and spinal section, with the patient showing paraplegia, signs of an upper motor neuron lesion and absence of deep nociception in pelvic limbs. The treatment of choice was T11 vertebrectomy, associated with the alignment of T10-12 with the introduction of pins and fixation with polymethylmethacrylate (PMMA) associated with ceftriaxone. Due to a lesion in the parietal pleura during the surgery, thoracostomy was chosen to introduce a chest tube, which remained in the patient for four days. In the postoperative period, the patient presented a satisfactory recovery, and it was recommended that tutors make a wheelchair to facilitate their mobility. The technique proved to be satisfactory for minimizing infections that could occur in open fractures and improving the patient's quality of life, avoiding chronic pain.
\end{abstract}

Keywords: veterinary surgery, spine, neurology, thoracostomy, spinal cord trauma.

\section{Instrodução}

A coluna vertebral tem como principais finalidades a sustentação corporal e a proteção de medula espinhal (ME), componente que desempenha importante papel no sistema nervoso central (SNC). A articulação entre os corpos vertebrais é preenchida, na sua maioria, pelo disco intervertebral (DI) (SINGH, 2017), o qual localiza-se entre as superfícies articulares dos corpos vertebrais adjacentes (BERGKNUT et al., 2013). A outra articulação entre vértebras se dá através dos processos articulares, que desempenham importante papel no alinhamento e estabilização da coluna vertebral (SINGH, 2017).

Lesões envolvendo a coluna vertebral não figuram entre as principais consequências de atropelamento, porém são frequentes (HALL, 2011). Por outro lado, o atropelamento é o principal causador de fraturas e luxações vertebrais (MENDES e ARIAS, 2012), podendo essas lesões levarem à eutanásia

\footnotetext{
*Recebido em 19 de março de 2021 e aceito em 15 de novembro de 2021.

**Universidade Federal do Paraná, setor Palotina. Programa de residência multiprofissional em medicina veterinária. Palotina, Paraná, Brasil. Autor para correspondência: alefe_luiz@hotmail.com.

***Universidade Estadual de Maringá, campus Umuarama. Programa de residência multiprofissional em medicina veterinária. Umuarama, Paraná, Brasil.

**** Médico veterinário autônomo. Clínica veterinária espaço animal. Maringá, Paraná, Brasil.

*****Universidade Cesumar, campus Maringá. Departamento de clínicas médica e cirúrgica de pequenos animais. Maringá, Paraná, Brasil.

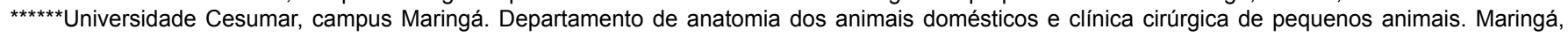
Paraná, Brasil.
} 
de pacientes, em decorrência das alterações irreversíveis e limitantes quanto à qualidade de vida deste (FIGHERA et al., 2008). O trauma automobilístico representa ampla casuística em animais de companhia, principalmente em cães e gatos. Os cães mais afetados possuem faixa etária jovem à meia idade (HALL, 2011).

Os sinais clínicos presentes em animais atropelados são inespecíficos e relacionados aos órgãos afetados (CULP e SILVERSTEIN, 2015). Quando lesões medulares são encontradas, o paciente apresentará, na maioria das vezes, déficit neurológico nas regiões caudais ao ponto da lesão (BRUCE et al., 2008; MENDES e ARIAS, 2012). O diagnóstico de fraturas e luxações, em sua maioria, é feito através de radiografia simples (MENDES e ARIAS, 2012), embora a tomografia computadorizada possa ser necessária (KINNS et al., 2006). O tratamento cirúrgico é o mais comumente realizado quando há lesões em coluna vertebral, visando reestabelecer a estabilidade e o alinhamento. Já o conservador poderá ser feito com terapias de reabilitação e tratamento medicamentoso para controle da dor e dos danos secundários causados pelo trauma (SHORES, 1992; JEFFERY, 2010). O prognóstico do paciente, bem como seus sinais clínicos, dependerá da intensidade da lesão na ME (PARK et al., 2012).

Objetivou-se relatar o caso de um canino, fêmea, recebido após trauma automobilístico com fratura exposta de coluna vertebral, onde optou-se pelo tratamento cirúrgico com vertebrectomia e estabilização com pinos e polimetilmetacrilato (PMMA).

\section{Relato de Caso}

Recebeu-se para atendimento um cão sem raça definida (SRD), fêmea, com quatro anos de idade, que havia sido atropelado por um automóvel há 10 dias, onde o tutor relatou que o mesmo apresentava uma ferida na região dorsal e ausência de movimentação nos membros pélvicos.

No exame físico, notou-se taquicardia, taquipneia, mucosas normocoradas, temperatura retal de $38,6^{\circ} \mathrm{C}$ e nada mais digno de nota referente aos demais sistemas avaliados. Percebeu-se uma área elevada na região dorsal, próximo à coluna toracolombar, que após tricotomia ampla da área, evidenciou-se uma solução de continuidade à pele, expondo a vértebra T11, indicando luxação ou fratura da coluna vertebral (Figura 1). Ao exame neurológico, os membros torácicos apresentavam normorreflexias, enquanto os membros pélvicos apresentavam alterações neurológicas compatíveis com síndrome do neurônio motor superior, como paraplegia, hiperreflexia patelar e hipertonia muscular, além de ausência de nocicepção, onde o paciente não reagiu ao teste de dor profunda, revelando grau $\mathrm{V}$ de lesão medular. $\mathrm{O}$ paciente foi submetido a analgesia após o exame neurológico, com administração de morfina $0,3 \mathrm{mg} / \mathrm{kg}$, dipirona $25 \mathrm{mg} / \mathrm{kg}$, meloxicam $0,1 \mathrm{mg} /$ $\mathrm{kg}$ e antibioticoterapia, com amoxicilina $20 \mathrm{mg} /$ kg. Realizou-se a limpeza do local da lesão com solução fisiológica $0,9 \%$ e compressas estéreis. Após a higienização, a ferida foi coberta com uma compressa estéril e envolvida com uma atadura de crepom, a fim de reduzir a exposição óssea e evitar o aumento da população bacteriana local. O paciente foi, então, encaminhado para radiografia de tórax e coluna toracolombar, e coleta de sangue para realização de hemograma, bioquímica sérica (ALT, FA, ureia e creatinina) e glicemia.

Figura 1: Lesão em região dorsocostal em cão SRD, de quatro anos de idade, recebido dez dias após episódio de atropelamento, evidenciando-se exposição de vértebra T11, indicando luxação e/ou fratura vertebral traumática.

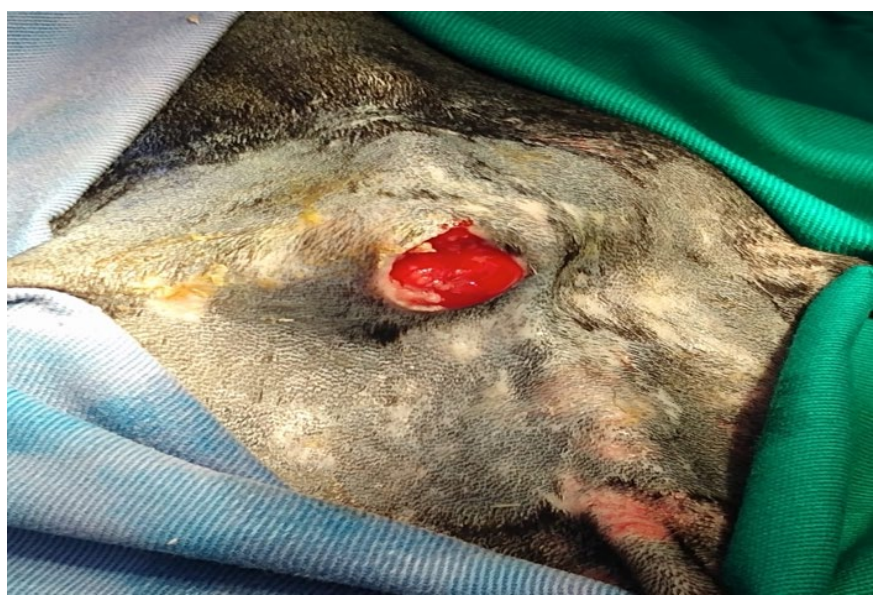

O laudo radiográfico evidenciou luxação da articulação entre T11 e T12, com exposição parcial do corpo vertebral, faceta articular e processos articulares de T11, além de fratura e luxação das $10^{\mathrm{a}}, 11^{\mathrm{a}}, 12^{\mathrm{a}}$ e $13^{\mathrm{a}}$ costelas de ambos hemitórax (Figura 2). O hemograma apresentou leucocitose por neutrofila, onde os demais resultados encontravam-se dentro dos padrões de referência (Tabela 1). Os exames bioquímicos obtiveram níveis desejáveis para a espécie avaliada (Tabela 2). O índice glicêmico revelou hiperglicemia (173mg/dL - Referência 60 a 120mg/dL).

Figura 2: Radiografia pré-operatória de tórax e coluna toracolombar de cão SRD de quatro anos de idade, recebido após episódio de atropelamento. Projeções latero-lateral direita $(A)$ e ventro-dorsal (B). Evidencia-se em A: luxação da articulação entre T11 e T12, com desvio dorsal do eixo de coluna vertebral e limites caudais de T11 na margem da pele, sugerindo exposição do tecido ósseo; fratura em processo espinhal de T8. Evidencia-se em B: desvio de eixo de coluna vertebral ao nível de T11-12, além de fratura e luxação das $10^{\mathrm{a}}, 11^{\mathrm{a}}$, $12^{\mathrm{a}}$ e $13^{\mathrm{a}}$ costelas de ambos hemitórax.
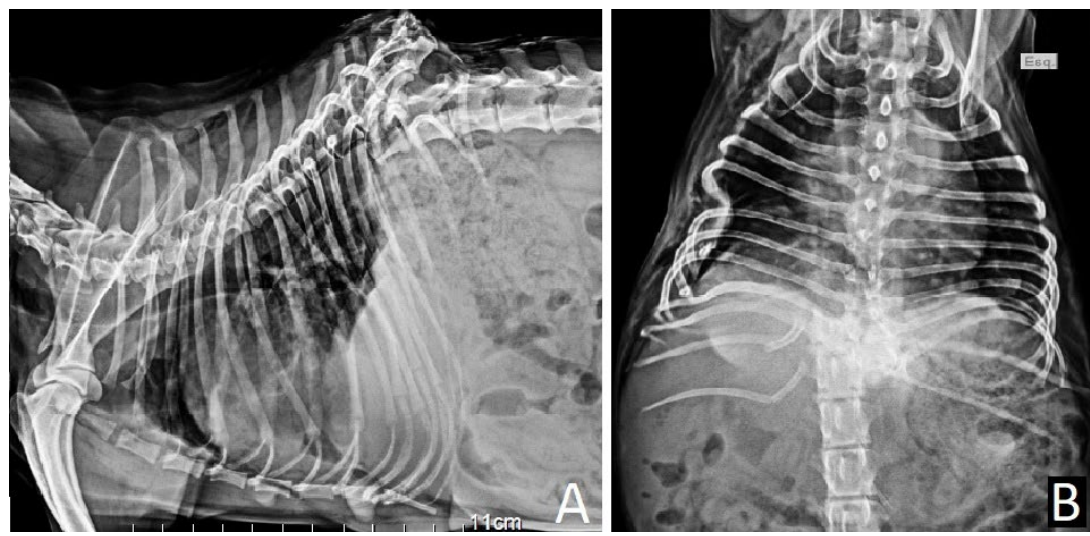
Tabela 1: Resultado de hemograma realizado em cão SRD de quatro anos de idade, recebido após episódio de atropelamento. Observa-se em eritrograma resultados dentro dos valores de referência; Leucograma indica leucocitose por neutrofilia; Plaquetograma indica resultados dentro dos valores de referência.

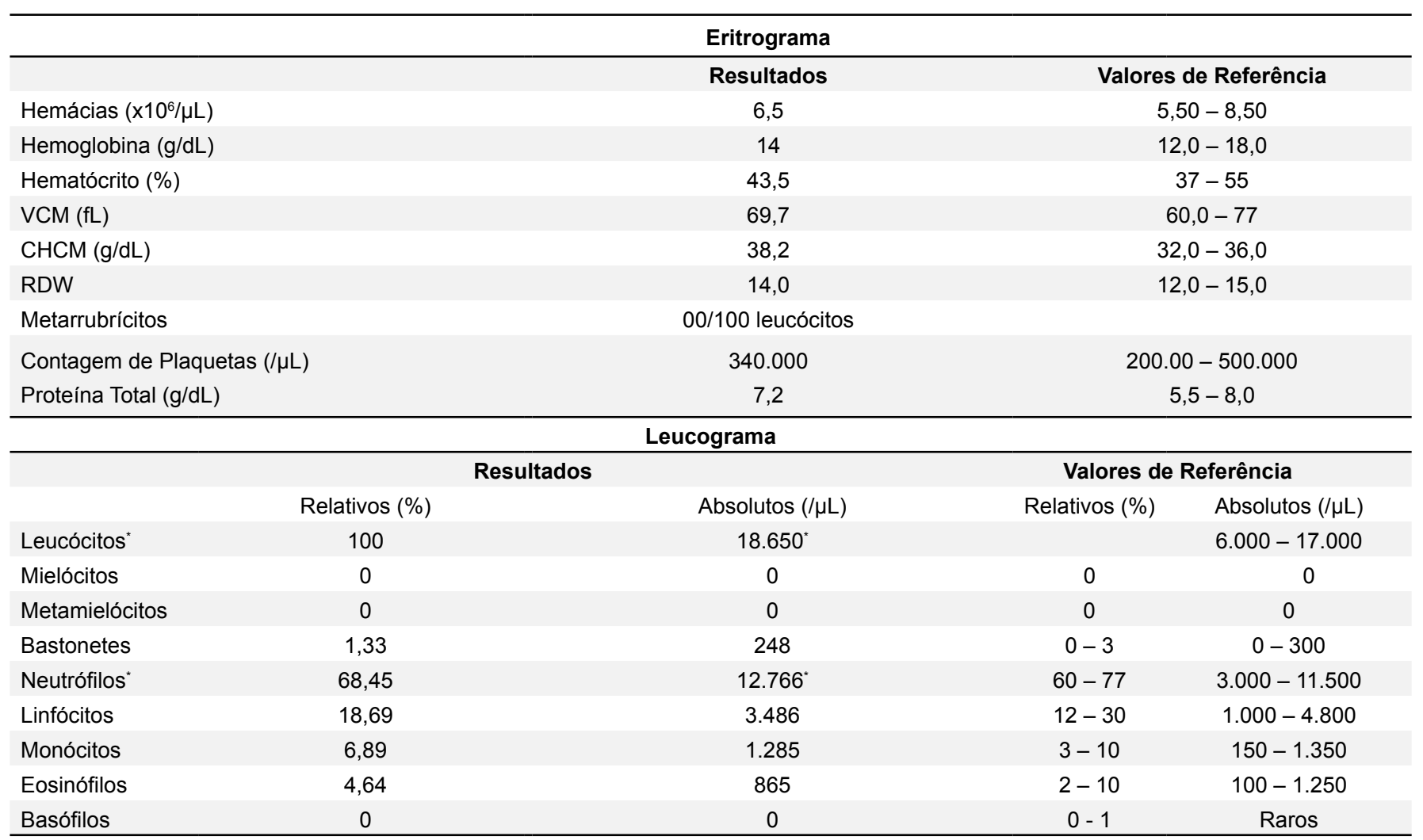

Tabela 2: Resultado de bioquímica sérica realizado em cão SRD de quatro anos de idade, recebido após episódio de atropelamento. Observa-se todos os resultados dentro dos valores de referência.

\begin{tabular}{lcc}
\hline & Bioquímicos & \\
\hline & Resultados & Valores de Referência \\
Alanina Aminotransferase - ALT & $95(\mathrm{U} / \mathrm{L})$ & $21-102(\mathrm{U} / \mathrm{L})$ \\
Fosfatase Alcalina - FA & $154(\mathrm{U} / \mathrm{L})$ & $20-156(\mathrm{U} / \mathrm{L})$ \\
Ureia & $21 \mathrm{mg} / \mathrm{dL}$ & $10-28 \mathrm{mg} / \mathrm{dL}$ \\
Creatinina & $0,76 \mathrm{mg} / \mathrm{dL}$ & $0,5-1,5 \mathrm{mg} / \mathrm{dL}$ \\
\hline
\end{tabular}

Estando a maioria dos resultados laboratoriais satisfatórios, o paciente foi encaminhado para a cirurgia de estabilização da coluna vertebral. Inicialmente, fez-se a medicação pré-anestésica com morfina $0,5 \mathrm{mg} / \mathrm{kg}$ associada à acepromazina $0,05 \mathrm{mg} / \mathrm{kg}$ administrados pela via intramuscular. Após 15 minutos, obteve-se o acesso venoso do paciente através da veia cefálica, colocando o mesmo em fluidoterapia com ringer com lactato em uma taxa de infusão de $5 \mathrm{~mL} / \mathrm{Kg} / \mathrm{hora}$. Fez-se a antibioticoterapia préoperatória com cefalotina $30 \mathrm{mg} / \mathrm{kg}$ pela via intravenosa 30 minutos precedentes à incisão cirúrgica. Procedeu-se para a indução anestésica com propofol $6 \mathrm{mg} / \mathrm{kg}$, onde após a perda dos reflexos, fez-se a intubação orotraqueal, mantendo a anestesia do paciente com isoflurano administrado em oxigênio a $100 \%$.

Então, o mesmo foi posicionado em decúbito esternal a fim de possibilitar a exploração da coluna vertebral. Foi feita a antissepsia do campo cirúrgico com três séries de clorexidine $2 \%$ e, posteriormente, três de álcool $70 \%$ na região ao redor da ferida, e com solução fisiológica $\mathrm{NaCl} 0,9 \%$ da ferida. A incisão cirúrgica foi feita três centímetros cranial e caudalmente ao ferimento, com debridamento das bordas da ferida. Após divulsão da musculatura epaxial adjacente às vértebras, identificou-se o corpo vertebral de T11 totalmente desalinhado do eixo da coluna, com constatação de secção da medula vertebral na altura da articulação T11-12. Tendo em vista o tempo de exposição da fratura, bem como a secção medular, decidiu-se pela remoção da vértebra exposta a fim de diminuir os riscos de infecção no sítio cirúrgico. Para tanto, continuou-se a divulsão do tecido muscular vertebral até a articulação de T1011, onde, com auxílio de uma lâmina de bisturi, promoveu-se a separação da face articular de T11 do disco intervertebral, bem como desarticulação dos processos articulares entre T10-11, possibilitando a completa remoção de T11 (Figura 3). Após a remoção da vértebra, houve uma pequena lesão na pleura torácica parietal, causando pneumotórax iatrogênico. 
Figura 3: Vista dorsal de vértebra T11 removida da de coluna toracolombar de cão SRD de quatro anos de idade, recebido após episódio de atropelamento em consequência da exposição após luxação. Seta: Fragmento do processo transverso direito; Ponta de seta: Processo articular cranial; Estrela: Processo articular caudal; *: lâmina dorsal após remoção do processo espinhoso

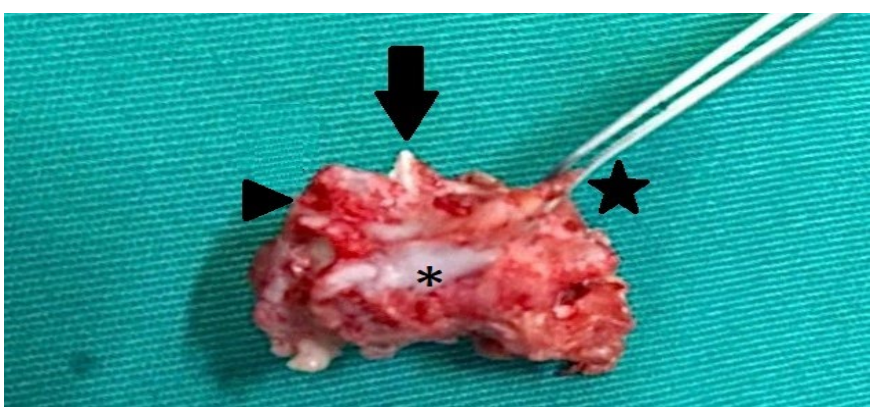

A estabilização do defeito cirúrgico foi conseguida através do alinhamento manual dos corpos vertebrais de T10 e 12, com aposição das superfícies articulares. Após o alinhamento, foram introduzidos pinos cirúrgicos, sendo dois deles fios de Kirschner 1,5 em forma de " $X$ ", atingindo ambos os corpos vertebrais a serem fixados, e mais seis fios de Schanz, sendo quatro 2,0 e dois 1,5 nos corpos vertebrais de T10 e T12, organizados um do lado esquerdo e dois do lado direito de ambas as vértebras. As extremidades excedentes dos pinos restantes, fixados às vértebras, foram seccionados à altura dos processos espinhosos das vértebras adjacentes, e, então, procedeu-se para a fixação dos fios metálicos com cimento ósseo estéril à base de polimetilmetacrilato (PMMA), de ambos os lados das vértebras (Figura 4). O cimento foi manipulado com adição de ceftriaxona na proporção de 1:10 (ceftriaxona:PMMA), a fim de reduzir a possível contaminação em tecidos moles e vértebras. Secundário à constatação de secção medular, optou-se pela não realização da descompressão por laminectomia dorsal. Após a secagem do cimento, realizou-se a aproximação da musculatura epaxial em padrão sultan com fio náilon 2-0, síntese de subcutâneo com fio náilon 2-0 em padrão simples contínuo em zigue-zague, e sutura de pele com náilon 2-0 e padrão simples interrompido.

Figura 4: Trans-cirúrgico de estabilização de vértebras torácicas de cão SRD de quatro anos de idade, recebido após episódio de atropelamento. Aspecto após a remoção de T11, com aplicação dos pinos em T10 e T12 e fixação desses com PMMA estéril associado à ceftriaxona

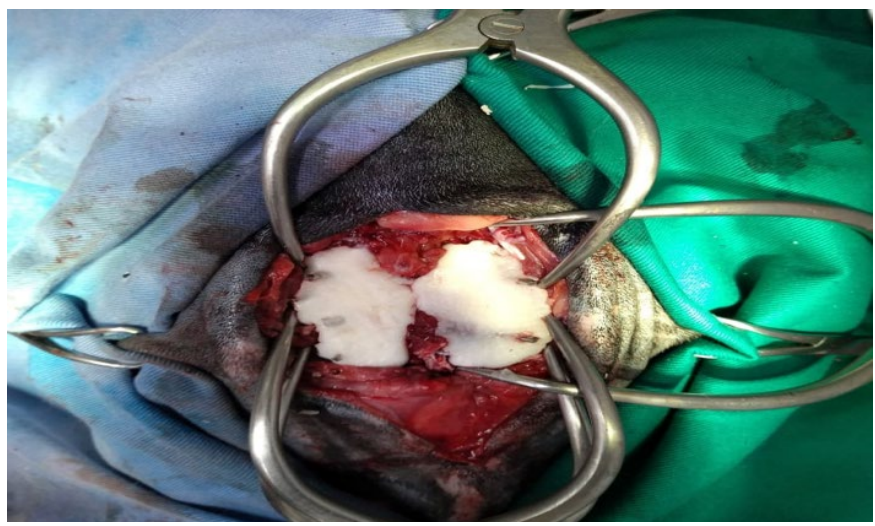

Em decorrência do pneumotórax iatrogênico, decidiu-se pela toracostomia. Utilizou-se uma sonda urinária calibre 14 , onde foram feitos orifícios por sua extensão a fim de promover melhor drenagem do ar torácico. Dessa forma, fez-se uma pequena incisão de pele ao nível da articulação costocondral do lado direito do tórax, na proximidade da $11^{a}$ costela. Com auxílio de uma pinça hemostática, a sonda foi introduzida pela incisão de pele, criando um túnel subcutâneo até chegar ao nono espaço intercostal, através do qual o tubo foi inserido rompendo a musculatura intercostal externa e interna. Após a sua colocação por completo, realizou-se a fixação do mesmo com sutura de bailarina, implantação de uma torneira de três vias em sua extremidade externa e cobertura da ferida cirúrgica, bem como da inserção do tubo, com uma atadura. Fez-se então a drenagem do ar torácico.

O animal foi mantido sob cuidados veterinários em internamento por mais quatro dias, período no qual foi mantido com tubo de toracostomia, drenando-o duas vezes ao dia. A partir do terceiro dia, a drenagem do tubo foi improdutiva, permitindo a sua remoção no quarto dia de internamento pós-cirúrgico. Durante o internamento, o paciente foi mantido sob antibioticoterapia com cefalotina $30 \mathrm{mg} / \mathrm{kg}$ e analgesia com morfina $0,3 \mathrm{mg} / \mathrm{kg}$ a cada 12 horas, dipirona $25 \mathrm{mg} / \mathrm{kg}$ a cada oito horas e meloxicam $0,1 \mathrm{mg} / \mathrm{kg}$ a cada 24 horas. Após a alta médica, receitou-se amoxicilina com clavulanato $25 \mathrm{mg} / \mathrm{kg}$ a cada 12 horas durante 10 dias, cloridrato de tramadol $4 \mathrm{mg} / \mathrm{kg}$ a cada 12 horas durante cinco dias e dipirona $25 \mathrm{mg} / \mathrm{kg}$ durante sete dias. Após 15 dias do procedimento, o paciente retornou para remoção dos pontos, identificando completa cicatrização da ferida. Ainda, fez-se uma nova radiografia pós-operatória (Figura 5), identificando alinhamento completo da coluna vertebral. O tutor relatou que o animal se encontrava ativo e saudável, sendo então recomendado a confecção de uma órtese (cadeira de rodas) para auxiliar na movimentação do paciente após, em média, 60 dias da cirurgia, tempo para que ocorra a cicatrização necessária. Através de contato telefônico 40 dias após o procedimento, o proprietário confirmou ausência de complicações ou sinais de dores no cão.

Figura 5: Radiografia pós-operatória da coluna vertebral nos segmentos torácico e lombar de cão SRD de quatro anos de idade, recebido após episódio de atropelamento. Projeções látero-lateral direita $(A)$ e ventro-dorsal (B). Evidencia-se presença de estrutura amorfa e radiopaca em região dorsal aos corpos vertebrais T9 a T13 (PMMA), acompanhado de oito pinos metálicos, e alinhamento do eixo da coluna vertebral
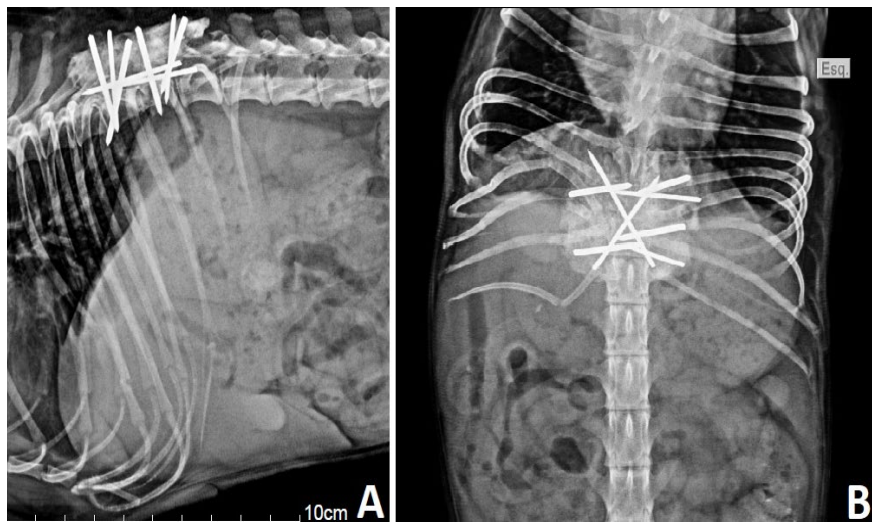


\section{Discussão e Conclusões}

As fraturas e luxações vertebrais decorrentes de eventos traumáticos são as principais causas de danos neurológicos em pequenos animais (JEFFERY, 2010). Embora as fraturas de ossos longos sejam mais comuns em animais vítimas de atropelamento, principalmente aquelas que envolvam membros pélvicos (HALL, 2011; CULP e SILVERSTEIN, 2015), tal fato não foi identificado no animal do relato em questão. Houve luxação de coluna vertebral e fraturas e luxações de costelas, porém sem comprometimento sistêmico, não havendo instabilidade torácica ou dispneia. A ausência de instabilidade torácica pode ser justificada pela ocorrência de fraturas e luxações de costelas pertencentes ao terço caudal da região costal, recoberto pela cúpula diafragmática, sendo que essa mesma alteração em costelas craniais poderia gerar instabilidade de parede torácica. Conforme indicado por Mendes e Arias (2012), os atropelamentos são as principais causas de fraturas e luxações da coluna vertebral, sendo esse o motivo para a intervenção no paciente em questão. Ainda, conforme Pereira et al. (2019) indicou, o segmento toracolombar da medula espinhal também foi o afetado nesse caso, confirmando a sua predisposição para injúrias em eventos traumáticos.

Os traumatismos envolvendo cães são responsáveis por causar dores severas, em decorrência das lesões ocasionadas em ossos e tecidos moles. A reação endócrina é a de liberação de hormônios de estresse em tais situações, como as catecolaminas e cortisol (SRITHUNYARAT et al., 2017), sendo tais substâncias inibidoras competitivos de um outro hormônio, a insulina, ocupando seus receptores quando em concentrações elevadas. Sendo assim, situações traumáticas são correlacionadas com episódios de hiperglicemia nos momentos pós-trauma (JERICÓ, 2015), sendo essa a justificativa proposta para a hiperglicemia apresentada pelo paciente no momento do atendimento primário.

A leucocitose por neutrofilia identificada no leucograma do paciente pode ser representada como um leucograma de estresse, onde o estresse foi causado pelo trauma, gerando dor e liberação de catecolaminas e cortisol, tendo efeito de aumento da contagem de células de defesa, principalmente neutrófilos e linfócitos (BENSCHOP et al., 1996; THRALL, 2007). Outro fator incriminado é a inflamação dos tecidos adjacentes à lesão, onde são gerados estímulos endógenos com citocinas pró-inflamatórias para que sejam produzidas novas linhagens de células de defesa (THRALL, 2007). Ainda, fraturas expostas são predispostas a ocorrência de infecções bacterianas (HORTA e REZENDE, 2014; DECAMP et al., 2016). Considerando a cronicidade da exposição óssea, a infecção bacteriana já poderia estar instalada no sítio da lesão (DECAMP et al., 2016), fato que também corrobora para que haja aumento das células de defesa.

Fraturas expostas são aquelas em que há uma comunicação externa ao osso, seja de forma direta ou indireta. A graduação dessas fraturas determina a gravidade do quadro, bem como o potencial de contaminação da ferida e lesão de tecidos moles adjacentes. Fraturas de grau I são aquelas causadas devido à pressão do osso em direção à pele, gerando sua abertura, são menores do que um centímetro e com menor potencial de infecção. As de grau II são as que possuem mais de um centímetro, com lesão de tecidos moles mais evidente e contaminação mais presente. Já as de grau III são aquelas com comprometimento vascular e neural, com focos necróticos e perda parcial ou total de sensibilidade local, além de contaminação evidente presente (HORTA e REZENDE, 2014). Considerando a extensão da lesão em pele do paciente relatado, bem como a evidente lesão subcutânea e muscular mostrada na figura 1, a presente fratura foi classificada como grau II.

Embora a radiografia simples seja a mais aplicável para a identificação de fraturas ou luxações, a tomografia computadorizada apresenta melhor sensibilidade para o diagnóstico de alguns tipos de fraturas vertebrais, podendo ambas serem associadas em quadros de instabilidade pequena e/ou pequenos deslocamentos de fragmentos vertebrais, principalmente quando a lesão acomete apenas um dos compartimentos vertebrais (KINNS et al., 2006). A ressonância magnética pode ser útil no diagnóstico de lesões traumáticas através da mensuração dos danos causados em tecidos moles e na medula espinhal, podendo fornecer aspectos de prognóstico do paciente, embora as alterações ósseas sejam suficientemente visualizadas na tomografia e/ou radiografia (JOHNSON et al., 2012).

O entendimento do potencial infeccioso de feridas abertas é essencial para a tomada de decisão quanto ao tratamento. Em decorrência da abertura dos tecidos moles e contato ósseo com o meio externo, o leito cirúrgico trona-se susceptível à ação de microrganismos do ambiente e até da flora dérmica do paciente (HORTA e REZENDE, 2014). Portanto, o tratamento dessas fraturas deve levar em conta alternativas para minimizar os riscos de infecções. O uso de PMMA associado a antibacterianos é uma técnica já conhecida e utilizada como método de reduzir a contaminação em fraturas infectadas. O cimento ósseo promoverá liberação lenta do antibiótico por vários dias, promovendo ação tópica satisfatória, a fim de reduzir a potencial contaminação e evitar a formação de quadros infecciosos (AZI et al., 2010). O uso da ceftriaxona manipulada ao PMMA mostrouse uma forma eficaz e de baixo custo para ação tópica em feridas contaminadas, revelando menores índices de infecção pós-cirúrgica em relação a pacientes que utilizaram somente a terapia antibiótica sistêmica (ALONGE e FASHINA, 2000; LUBIS et al., 2005). Em virtude da contaminação conhecida, a técnica em questão foi adotada visando reduzir as chances de infecções bacterianas no local da lesão, demonstrando efeito positivo considerando-se a ausência de sinais clínicos de infecção bacteriana local no período pós-operatório.

Outro fator indispensável para a tomada de decisão quanto ao tratamento de pacientes acometidos por lesões medulares envolve a graduação dos sinais de disfunção neurológica, variando de I a V, sendo: I quando o paciente apresenta apenas dor à palpação do segmento lesionado, sem demais alterações neurológicas; II quando identifica-se déficit proprioceptivo e/ ou ataxia em membros; III em circunstâncias que o paciente apresenta uma paresia não ambulatorial; IV quando somados os sinais em III associado a perda da sensibilidade superficial; $\checkmark$ quando há progressão e perda da sensibilidade profunda (BRUCE et al., 2008). Um estudo realizado por Bruce et al. (2008), evidenciou que o trauma veicular foi o principal causador de fraturas ou luxações vertebrais em cães, bem como o segmento toracolombar da medula espinhal também foi o mais afetado. Além disso, os pacientes com lesão neurológica classificada até grau II foram tratados de forma conservadora, enquanto a terapia cirúrgica foi a de escolha para os pacientes que possuíam déficit locomotor; dentre esses últimos pacientes, os de grau $\mathrm{V}$ foram os mais susceptíveis à eutanásia devido 
aos intensos danos neurológicos acarretados. Mesmo que o cão envolvido nesse caso apresentasse-se com grau $V$ de acometimento medular, o seu baixo peso corporal, bem como a vontade dos tutores em cuidá-lo foram determinantes para a opção ao tratamento cirúrgico em detrimento à eutanásia.

Para a decisão cirúrgica de lesões envolvendo os segmentos vertebrais, a teoria dos três compartimentos é aplicada. Esta foi inicialmente proposta na medicina humana por Denis (1983), sendo adaptada para a veterinária por Shores et al. (1992), sendo importante parâmetro para decisão entre tratamento cirúrgico e conservador. Esse estudo demonstra que a vértebra possui três porções, ditas compartimentos: dorsal, o qual compreende a lâmina dorsal, processo espinhoso e ligamentos; médio, abrangendo o ligamento longitudinal dorsal, anel dorsal e porção dorsal do corpo vertebral; e ventral, com parte ventral do corpo vertebral, anel ventral e ligamento longitudinal ventral. Quando a fratura envolve dois ou três desses compartimentos, ocorre instabilidade vertebral e há necessidade de estabilização cirúrgica (JEFFERY, 2010). Tal teoria foi confirmada por Diamante et al. (2020) para sua aplicabilidade nas lesões toracolombares do cão, corroborando para a tese de que a instabilidade se instala quando dois ou mais compartimentos são afetados. Tratando-se de casos de luxação completa da coluna, como aqui relatado, a instabilidade é instalada, visto que os três compartimentos vertebrais são acometidos.

O método de estabilização mais optado nos tratamentos de fraturas ou luxações vertebrais nos segmentos torácico e lombar é a associação de pinos implantados nos corpos vertebrais, com polimetilmetacrilato fixando-os. Dessa forma, a técnica visa manter $\mathrm{a}$ (s) vértebra(s) afetada(s) estável(is), fixando-a(s) às adjacentes (BLASS e SEIM, 1984; JEFFERY, 2010). É possível realizar-se a alteração dos implantes escolhidos, visto que parafusos podem ser utilizados ao invés dos pinos, porém há maiores chances de complicações futuras, visto a possibilidade de falha do implante quanto a sua fixação no corpo vertebral ou na aderência ao PMMA (GARCIA et al., 1994). Para o caso em questão, a técnica utilizando pinos mostrou-se satisfatória tendo em vista a ausência de complicações relacionadas à falha dos implantes utilizados. A escolha dos pinos em detrimento aos parafusos foi tomada tendo em vista a melhor eficácia da técnica, bem como a maior facilidade de aplicação e menor custo. Outras modalidades de estabilização cirúrgica através de métodos abertos podem incluir: uso de placa Lubra (KRAUSS et al., 2012) e banda de tensão associada a fio de Kirschner (VOSS e MONTOVAN, 2004), porém a primeira apresenta custo mais elevado e a segunda somente é indicada para pacientes de baixo peso corporal. Parafusos pediculados também são alternativa de estabilização. Já opções minimamente invasivas podem ser obtidas através da aplicação de fixadores lineares externos, com auxílio de fluoroscopia transcirúrgica (WHEELER et al., 2007; BITTERLI et al., 2020), as quais não forma opção devido à necessidade de alinhamento do eixo da coluna.

A secção da medula espinhal indica um prognóstico desfavorável ao paciente, visto a impossibilidade de recuperação dos reflexos e tônus motor (JEFFERY, 2010). Devido ao grau do impacto sofrido pelo cão, houve um deslocamento exacerbado de T11 em relação a T12, culminando com sua secção. Araújo et al. (2015) identificaram um prognóstico pior nos animais com secção medular em comparação com os quais a medula permaneceu sem ruptura, onde tais animais, quando submetidos à cirurgia, passaram somente pela estabilização e fixação da coluna, sem que houvesse realização da descompressão por laminectomia dorsal. Todos os pacientes acometidos por secção apresentaram-se com grau $\mathrm{V}$ de acometimento neurológico, porém esse grau e/ou a associação com ruptura medular não devem ser totalmente desencorajadores para a realização do tratamento, visto que alguns pacientes possuem a capacidade de desenvolver o caminhar involuntário, dito caminhar espinhal (ARAÚJO et al., 2015; ARAÚJO et al., 2017), que, embora descoordenado, detêm a capacidade de fornecer melhor qualidade de vida ao paciente. Também, como alternativa à eutanásia, o uso de órteses na forma de cadeira de rodas também já foi descrito para pacientes grau $V$ sem recuperação dos movimentos, de forma a facilitar o manejo dos tutores e melhorar a qualidade de vida do cão (SILVA et al., 2013).

Em virtude da lesão grave em medula espinhal nesse paciente, a preocupação inicial era referente ao desenvolvimento de mielomalácia progressiva, a qual ocorre por causas desconhecidas, gerando um comprometimento vascular intenso na medula espinhal, culminando com isquemia progressiva, cranial e caudal ao local de lesão. Tal alteração é mais passível de ocorrência em pacientes com lesão de grau V (ZILIO e ARIAS, 2013). No estudo realizado por Zilio e Arias (2013), identificou-se a região toracolombar da medula espinhal como a mais frequente para a ocorrência de mielomalácea. Nesse mesmo trabalho, também foi evidenciado que o trauma medular representou a segunda maior causa desencadeante da alteração degenerativa progressiva, perdendo apenas para as doenças do disco intervertebral. Dessa forma, somando-se o grau da lesão desse paciente com a ocorrência de secção medular, a ocorrência de mielomalácia progressiva foi uma preocupação, embora esse distúrbio não tenha se instalado. Os sinais que poderiam indicar a sua ocorrência são: alteração de síndrome do neurônio motor superior para inferior, presença de respiração abdominal, perda do reflexo cutâneo do tronco cranial à lesão, perda do reflexo e tônus anal e morte, os quais podem ocorrer de horas a dias após a lesão (ZILIO e ARIAS, 2013), sendo que nenhum dos sinais descritos foram identificados no cão.

O prognóstico é variável, visto que as principais complicações são secundárias aos distúrbios neurológicos nela ocasionados em decorrência do trauma (SANTORO e ARIAS, 2018). A principal sequela observada em pacientes acometidos por lesão medular é a incontinência, seja fecal ou urinária (PEREIRA et al., 2019), sendo nesse caso observada apenas a urinária, devido à retenção, sendo necessária a massagem vesical diária para esvaziamento da mesma. A extensão e profundidade da lesão na medula espinhal, bem como o intervalo entre a ocorrência do trauma até a intervenção cirúrgica e tratamento são cruciais na determinação do prognostico do paciente (PARK et al., 2012). As demais sequelas presentes nos animais acometidos podem incluir: déficits neurológicos permanentes, atrofia muscular e paralisia de membros, dependendo do segmento da coluna que foi afetado (SANTORO e ARIAS, 2018).

Foram consultados outros relatos de casos envolvendo remoção de vértebras, sendo a técnica de vertebrectomia mais utilizada em pacientes acometidos por neoplasias, podendo o neoplasma ser de origem vertebral ou paravertebral invadindo a coluna (CHAUVET et al., 1999; LIPTAK et al., 2020). Também foi encontrada a técnica para um caso de luxação crônica de coluna vertebral (MARINHO et al., 2014). Porém, não foram identificados casos envolvendo fraturas ou luxações com exposição de vértebras como causa de vertebrectomia total em cães, podendo esse ser um primo-relato de vertebrectomia para tratamento de luxação exposta de coluna vertebral em cão. 


\section{Referências}

ALONGE, T.; FASHINA, A.N. Ceftriaxone-PMMA beads - A slow release preparation? International Journal of Clinical Practice, v.54, n.6, p.353-355, 2000.

ARAÚJO, B.M.; FERNANDES, T.H.T.; BARAÚNA JÚNIOR, D.; BONELLI, M.A.; AMORIM, M.M.A.; TUDURY, E.A.

Desenvolvimento de caminhar espinal em cães paraplégicos com fraturas e luxações vertebrais toracolombares. Pesquisa Veterinária Brasileira, v.37, n.8, p.853-858, 2017.

ARAÚJO, B.M.; SILVA, A.C.; FIGUEIREDO, M.L.; FERNANDES, T.H.T.; BARAÚNA JÚNIOR, D.; BONELLI, M.A.; DIOGO, C.C.; AMORIM, M.M.A.; TUDURY, E. A. Observações clinico-cirúrgicas em fraturas e luxações vertebrais toracolombares em cães. Arquivo Brasileiro de Medicina Veterinária e Zootecnia, v.67, n.4, p.961-968, 2015.

AZI, M.L.; KFURI JÚNIOR, M.; MARTINEZ, R.; PACCOLA, C.A.J. Cimento ósseo com gentamicina no tratamento da infecção óssea: estudo da eluição in vitro. Acta Ortopédica Brasileira, v.18, n.1, p.31-34, 2010.

BENSCHOP, R.J.; RODRIGUEZ-FEUERHAHN, M.; SCHEDLOWSKI, M. Catecholamine-Induced Leukocytosis: early observations, current research, and future directions. Brain, Behavior, And Immunity, v.10, n.2, p.77-91, 1996.

BERGKNUT, N.; SMOLDERS, L.A.; GRINWIS, G.C.M.; HAGMAN, R.; LAGERSTEDT, A.; HAZEWINKEL, H.A.W.; TRYFONIDOU, M.A.; MEJI, B.P. Intervertebral disc degeneration in the dog. Part 1: Anatomy and physiology of the intervertebral disc and characteristics of intervertebral disc degeneration. The Veterinary Journal, v.195, n.3, p.282-291, 2013.

BITTERLI, T.; HAEUSSLER, T.C.; SCHMIDT, M.J.; PEPPLER, C.; KRAMER, M. Minimal invasive stabilization of thoracolumbar spinal fractures and luxations in dogs and cats using unilateral uniplanar external skeletal fixator. Veterinary Comparative Orthopedy and Traumathology, v.33, n.4, p.15-26, 2020.

BLASS, C.E.; SEIM, H.B. Spinal fixation in dogs using steinmann pins and methylmethacrylate. Veterinary Surgery, v.13, n.4, p.203210, 1984.

BRUCE, C.; BRISSON, B.; GYSELINCK, K. Spinal fracture and luxation in dogs and cats. Veterinary And Comparative Orthopaedics And Traumatology, v.21, n.3, p. 280-284, 2008.

CHAUVET, A.E.; HOGGE, G.S.; SANDIN, J.A.; LIPSITZ, D. Vertebrectomy, bone allograft fusion, and antitumor vaccination for the treatment of vertebral fibrosarcoma in a dog. Veterinary Surgery, v.28, n.6, p.480-488, 1999.

CULP, W.T.N.; SILVERSTEIN, D.C. Thoracic and abdominal trauma. In: SILVERSTEIN, D.C.; HOPPER, K. (Eds). Small Animal Critical Care Medicine. 2 ed. St. Louis: W.B. Saunders, 2015, p.728-733.

DECAMP, C.E.; JOHNSTON, S.A.; DEJARDIN, L.M.; SCHAEFER, S.L. Treatment of acute and chronic bone infections. In: . Brinker, Piermattei and Flo's handbook of small animal orthopedics and fracture repair. 5 ed., Philadelphia: Saunders Elsevier, p.174-179, 2016.

DIAMANTE, G.A.C.; MARINHO, P.V.T.; ZANI, C.C.; ARIAS, M.V.B. Ex-vivo evaluation of the three-column concept in canine thoracolumbar fractures. Arquivo Brasileiro de Medicina Veterinária e Zootecnia, v.72, n.4, p.1221-1230, 2020.

FIGHERA, R.A.; SILVA, M.C.; SOUZA, T.M.; BRUM, J.S.; KOMMERS, G.D.; GRAÇA, D.L.; IRIGOYEN, L.F.; BARROS, C.S.L. Aspectos patológicos de 155 casos fatais de cães atropelados por veículos automotivos. Ciência Rural, v.38, n.5, p.1375-1380, 2008.
GARCIA, J.N.P.; MILTHORPE, B.K.; RUSSELL, D.; JOHNSON, K.A. Biomechanical study of canine spinal fracture fixation using pins or bone screws with polymethylmethacrylate. Veterinary Surgery, v.23, n.5, p.322-329, 1994.

HALL, K. Canine trauma: literature review and evidence based medicine. Journal of Veterinary Emergency and Critical Care, v.21, n.5, p.572-575, 2011.

JEFFERY, N.D. Vertebral fracture and luxation in small animals. Veterinary Clinics of North America: Small Animal Practice, v.40, n.5, p.809-828, 2010.

JERICÓ, M. M. Doenças do Sistema endócrino e do metabolismo. In: JERICÓ, M.M.; ANDRADE NETO, J.P.; KOGIKA, M.M. (Eds.) Tratado de Medicina Interna de Cães e Gatos. 1 ed. Rio de Janeiro: Roca, 2015. p.1613-1808.

JOHNSON, P.; BELTRAN, E.; DENNIS, R.; TAEYMANS, $O$. Magnetic resonance imaging characteristics of suspected vertebral instability associated with fracture or subluxation in eleven dogs. Veterinary Radiology \& Ultrasound, v.53, n.5, p.552559, 2012.

KINNS, J.; MAI, W.; SEILER, G.; ZWINGENBERGER, A.; JOHNSON, V.; CACERES, A.; VALDÉS-MARTÍNEZ, A.; SCHWARTZ, T. Radiographic sensitivity and negative predictive value for acute canine spinal trauma. Veterinary Radiology \& Ultrasound, v.47, n.6, p.563-570, 2006.

KRAUSS, M.W.; THEYSE, L.F.H.; TRYFONIDOU, M.A.; HAZEWINKEL, H.A.W.; MEJI, B.P. Treatment of spinal fractures using Lubra plates. Veterinary And Comparative Orthopaedics And Traumatology, v.25, n.4, p.326-331, 2012.

LIPTAK, J.M.; VEYTSMAN, S.; KERR, S.; KLASEN, J. Multiple segment total en bloc vertebrectomy and chest wall resection in a dog with an invasive myxosarcoma. Veterinary Record Case Reports, v.8, n.2, p.1-9, 2020.

LUBIS, A.M.T.; TOBING, S.D.L.; SIREGAR, P.U. The use of ceftriaxone impregnated beads in the management of chronic osteomyelitis. Medical Journal of Indonesia, v.14, n.3, p.157-162, 2005.

MARINHO, P.V.T.; ZANI, C.C.; BIASI, F.; ARIAS, M.V.B. Total vertebrectomy for stabilisation of chronic spinal lumbar luxation in a paraplegic dog without nociception. Journal of Small Animal Practice, v.55, n.10, p.538-541, 2014.

MENDES, D.S.; ARIAS, M.V.B. Traumatismo da medula espinhal em cães e gatos: estudo prospectivo de 57 casos. Pesquisa Veterinária Brasileira, v.32, n.12, p.1304-1312, 2012.

PARK, E.H.; WHITE, G.A.; TIEBER, L.M. Mechanisms of injury and emergency care of acute spinal cord injury in dogs and cats. Journal Of Veterinary Emergency And Critical Care, v.22, n.2, p.160-178, 2012.

PEREIRA, D.T.; SCHWAB, M.L.; FERRARIN, D.A.; RIPPLINGER, A.; AIELLO, G.; HERCULANO, L.F.; WRZESINSKI, M.R.; RAUBER, J.S.; MORO, S.S.; MAZZANTI, A. Vertebral fractures and luxation in dogs. Acta Scientiae Veterinariae, v.47, n.1, p.1-7, 2019.

SANTORO, M.B.; ARIAS, M.V.B. Complicações observadas em cães e gatos com doenças neurológicas. Pesquisa Veterinária Brasileira, v.38, n.6, p.1159-1171, 2018.

SHORES, A. Spinal Trauma. Veterinary Clinics Of North America: Small Animal Practice, v.22, n.4, p.859-888, jul. 1992.

SILVA, C.L.; TOSATO, G.B.S.; GARCIA, J.N.N.; PITA, M.C.G. Reabilitação por implantação de cadeira em cão com secção medular torácica como alternativa à eutanásia: relato de caso. PUBVET, v.7, n.26, p.1-10, 2013. 
SINGH, B. Dyce Sack and Wensing's Textbook of Veterinary Anatomy. 5 ed. Philadelphia: Saunders Elsevier, 2017, p.1606.

SRITHUNYARAT, T.; HAGMAN, R.; HOGLUND, O.V.; STRIDSBERG, M.; OLSSON, U.; HANSON, J.; NONTHAKOTR, C.; LAGERSTEDT, A.; PETTERSSON, A. Catestatin, vasostatin, cortisol, and pain assessments in dogs suffering from traumatic bone fractures. Bmc Research Notes, v.10, n.1, p.1-10, 2017.

THRALL, M. A. Hematologia e Bioquímica Veterinária. 1. ed. São Paulo: Roca, 2007, 2007.
VOSS, K.; MONTAVON, P.M. Tension band stabilization of fractures and luxations of the thoracolumbar vertebrae in dogs and cats: 38 cases (1993-2002). Journal Of The American Veterinary Medical Association, v.225, n.1, p.78-83, 2004.

WHEELER, J.L.; LEWIS, D.D.; CROSS, A.R.; SEREDA, C.W. Closed fluoroscopic-assisted spinal arch external skeletal fixation for the stabilization of vertebral column injuries in five dogs. Veterinary Surgery, v.36, n.5, p.442-448, 2007.

ZILIO, D.M.; ARIAS, M.V.B. Mielomalácia hemorrágica progressiva em 14 cães. Pesquisa Veterinária Brasileira, v.33, n.2, p.219-228, 2013. 